\title{
EFFECTIVENESS OF DEEP VENOUS THROMBOSIS PREVENTION IN TOTAL HIP ARTHROPLASTY
}

\section{EFICIÊNCIA DA PREVENÇÃO DA TROMBOSE VENOSA PROFUNDA NA ARTROPLASTIA TOTAL DO QUADRIL}

\author{
Victor Martins Manfredi ${ }^{1}$ (1), Matheus BitTencourt Machado ${ }^{1}$ (i), Nícolas Giorgini Barbato ${ }^{1}$ (i), \\ EDMILSON TAKEHIRO TAKATA ${ }^{1,2}$ (D), EIFFEL TSUYOSHI DOBASHI ${ }^{1,2}$ (D)
}

1. Ifor Hospital, Institute of Fractures, Orthopedics and Rehabilitation, São Bernardo do Campo, SP, Brazil.

2. Federal University of São Paulo, São Paulo School of Medicine, São Paulo, SP, Brazil.

\section{ABSTRACT}

Objective: To determine the efficacy of Deep Venous Thrombosis (DVT) prophylaxis protocol in patients undergoing total hip arthroplasty (THA), and to verify differences in the rates of this complication when comparing primary replacement surgeries with revision surgeries. Methods: We conducted a retrospective study of patients operated between 2012 and 2018, with inclusion and non-inclusion criteria determined by the researchers. A protocol was created to compile data including 92 patients, amounting to 110 operated hips, divided by gender, age, laterality, among other criteria. For THA cases, low molecular weight heparin chemoprophylaxis was used, associated with the use of pneumatic and elastic compression, concomitant to deambulation as soon as possible. The detection of DVT was determined by clinical evaluation and imaging exams such as: simple radiographs, ultrasound, arterial and venous color doppler, and laboratory tests. Results: The use of the protocol was very effective in our study. Only one $(1.09 \%)$ case of deep venous thrombosis was found. Conclusion: The use of thromboprophylaxis for DVT is indispensable, as was clearly demonstrated by these cases. We observed only one (1.09\%) case of DVT in our series. Level of Evidence III, Retrospective Study.

Keywords: Arthroplasty Replacement Hip. Venous Thrombosis. Diagnosis. Primary Prevention. Combined Modality Therapy.

\section{RESUMO}

Objetivo: Determinar a eficácia de protocolo de profilaxia contra a Trombose Venosa Profunda (TVP) em pacientes submetidos à artroplastia total do quadril (ATQ) e verificar diferenças nas taxas desta complicação ao comparar as cirurgias de substituição primária com as de revisão. Métodos: Realizamos um estudo retrospectivo de pacientes operados entre 2012 e 2018, com critérios de inclusão e não inclusão determinados pelos pesquisadores. Foi criado um protocolo para a compilação de dados no qual foram incluídos 92 pacientes, estes com 110 quadris operados divididos por sexo, idade, lateralidade, entre outros critérios. Para os casos de ATQ, utilizamos a quimioprofilaxia com heparina de baixo peso molecular associada ao uso de compressão pneumática e elástica, concomitante à deambulação assim que possível. A detecção da TVP foi determinada pela avaliação clínica e por exames de imagem como: radiografias simples, exame ultrassonográfico, doppler colorido arterial e venoso e exames laboratoriais. Resultados: A utilização do protocolo se mostrou bastante eficaz em nosso estudo. Foi encontrado apenas um (1,09\%) caso de trombose venosa profunda. Conclusão: A utilização de tromboprofilaxia para a TVP é indispensável e consagrada nestes casos. Observamos apenas um (1,09\%) caso de TVP em nossa casuística. Nível de Evidência III, Estudo Retrospectivo.

Descritores: Artroplastia de Quadril. Trombose Venosa Profunda. Diagnóstico. Prevenção. Tratamento Multimodal.

Citation: Manfredi VM, Machado MB, Barbato NG, Takata ET, Dobashi ET. Effectiveness of deep venous thrombosis prevention in total hip arthroplasty. Acta Ortop Bras. [online]. 2021;29(6):293-296. Available from URL: http://www.scielo.br/aob.

\section{INTRODUCTION}

Total hip arthroplasty (THA) is considered an undisputed modality as a therapeutic surgical option for patients with degenerative arthritis. Among the undesirable complications of this type of intervention are deep vein thrombosis (DVT) and pulmonary thromboembolism (PE). ${ }^{1}$ As is well known, before the institution and application of protocols to combat and avoid such adversities, such as the use of anticoagulants, its incidence ranged from $55 \%$ to $80 \%$.
Some factors, previously recognized by aspects such as family history, advanced age, cardiomyopathies, chronic edema of the lower limbs, immobilization, obesity, sedentary lifestyle, use of medication (oral contraceptives or hormones), excessive blood loss, transfusion, among others, increase the risk of developing thromboembolism. There is a greater risk of developing this condition between the second and third weeks of the postoperative period, as $29 \%$ of thrombi originate in the first 12 days, and $23 \%$ between 22 and

All authors declare no potential conflict of interest related to this article.

The study was conducted at the Ifor Hospital, Institute of Fractures, Orthopedics and Rehabilitation.

Correspondence: Victor Martins Manfredi. Av. Dr. Alberto Benedetti, 365, ap. 31, Santo André, SP, Brazil, 09030340. victormanfredi27@gmail.com 
24 days after surgery. ${ }^{2}$ Ultrasonography with venous Doppler of the lower limbs and contrast venography assist the diagnosis. ${ }^{3,4}$ The routine administration of preventive methods for intravenous thrombosis in patients undergoing THA is consensual among all orthopedists; however, no universal protocol has been established, much less which medication to apply or the ideal time of use, as one may notice by the scarcity of studies on this subject. ${ }^{5}$

Mechanical methods of prophylaxis for DVT, such as the use of elastic compression stockings, can reduce its appearance by more than $50 \%$, and the association with active and passive movement of the lower limbs and early ambulation would be considered auxiliary prophylactic measures. ${ }^{6}$ Prophylactic drugs, such as vitamin $\mathrm{K}$ inhibitors and low molecular weight heparin, according to the orthopedic literature, also help to reduce the rates of these adversities.

Despite the undeniable importance of the benefit of using prophylactic methods for the prevention of DVT in patients who underwent THA, there is no consensus in the literature on which method has the best results. In a systematic review, through 26 trials with 2,600 individuals, we found that both low molecular weight heparin (LMWH) and unfractionated heparin (UFH) are effective in reducing DVT. ${ }^{7}$ There are also reports that $\mathrm{LMWH}$ is significantly more effective and safer when compared to the use of UFH. Regarding the LMWH dose, 40mg applied subcutaneously once a day would be sufficient and effective. ${ }^{8}$

Therefore, our study has as its primary objective to determine the effectiveness of the prophylaxis protocol against DVT that we use in our service in patients undergoing THA. Secondarily, we will verify if there were differences in the rates of this complication when comparing primary replacement surgeries with revision ones.

\section{MATERIAL AND METHODS}

Firstly, the research project of this work was submitted to bioethical evaluation by the Research Ethics Committee of Plataforma Brasil under the CAEE registration and approved for completion under the opinion number 22051819.3.0000.5625.

A retrospective and observational study was conducted based on the analysis of medical records of patients who underwent total hip arthroplasty between 2012 and 2018 at the Institute of Fractures, Orthopedics and Rehabilitation - Hospital Ifor.

The following inclusion criteria were used:

1. Patients of both sexes; older than 18 years;

2. Postoperative follow-up of at least one year;

3. Carriers of unilateral or bilateral hip joint affection (primary or secondary);

4. No history of coagulopathies;

5. No DVT history;

6. Who present complete medical records;

7. Have been submitted to the institutional DVT prevention protocol. The non-inclusion criteria used in this research were:

1. Patients with incomplete medical records;

2. Patients who did not adhere to the institutional protocol;

3. Patients who did not sign the free and informed consent form for the use of their medical records.

We devised an investigation protocol so that data could be collected and then tabulated using Excel (Microsoft), which consisted of the following information: order number; age at surgery; sex; affected side; ethnicity; weight and height; body mass index (BMI); nosological diagnosis; etiological diagnosis; comorbidities (diabetes, systemic arterial hypertension); continuous use medications; family history of deep vein thrombosis; determination of the degree of hip arthrosis according to the classification by Kellgren \& Lawrence ${ }^{9}$; type of prosthesis used (primary or revision, cemented or cementless).

The methodology used to classify and assess the degree of degenerative hip osteoarthritis followed the methodology proposed by Kellgren \& Lawrence ${ }^{9}$ (Table 1 ).

\begin{tabular}{c|c}
\multicolumn{2}{c}{ Table 1. Kellgren-Lawrence Classification (1957) } \\
\hline Grade & Description \\
\hline 0 & definite absence of x-ray changes of osteoarthritis \\
\hline 1 & doubtful joint space narrowing and possible osteophytic lipping \\
\hline 2 & definite osteophytes and possible joint space narrowing \\
\hline 3 & $\begin{array}{r}\text { moderate multiple osteophytes, definite narrowing of joint space } \\
\text { and some sclerosis and possible deformity of bone ends }\end{array}$ \\
\hline 4 & $\begin{array}{r}\text { large osteophytes, marked narrowing of joint space, } \\
\text { severe sclerosis and definite deformity of bone ends }\end{array}$ \\
\hline
\end{tabular}

According to the adopted criteria, 92 patients were included, of which 56 (60.87\%) female and 36 (39.13\%) male, 71 (77.17\%) were white, nine $(9.78 \%)$ of other ethnicities, seven $(7.60 \%)$ black, and five $(5.43 \%)$ asian. The mean age of patients was 57.42 years (minimum 26.75 years old and maximum 81.00). Of the total number of patients, 110 hips were operated, 55 (50.00\%) of which underwent arthroplasty on the right hip and 55 (50.00\%) on the left, and 18 (19.57\%) patients underwent bilateral hip arthroplasty. According to the classification of Kellgren and Lawrence, 17 (18.47\%) patients were classified as having type I degenerative arthritis, 06 (6.52\%) type II, 26 (28.26\%) type III, and 43 (46.73\%) type IV. The mean weight of patients found was $75.2 \mathrm{~kg}$ (minimum of $50 \mathrm{~kg}$ and maximum of $110 \mathrm{~kg}$ ) and the mean height of patients was $166 \mathrm{~cm}$ (minimum of $150 \mathrm{~cm}$ and maximum of $191 \mathrm{~cm}$ ). The mean body mass index (BMI) found was $27.11 \mathrm{~m}^{2} / \mathrm{kg}$ (minimum of $18.4 \mathrm{~m}^{2} / \mathrm{kg}$ and maximum of $37.2 \mathrm{~m}^{2} / \mathrm{kg}$ ). As for the etiology, 64 (69.56\%) had primary degenerative arthritis, nine (9.78\%) other causes, eight (8.69\%) had osteonecrosis, five (5.43\%) hip developmental dysplasia, two (2.17\%) had sickle cell anemia, two $(2.17 \%)$ traumatic sequelae, and two $(2.17 \%)$ were of infectious origin. Of the total, 64 (69.56\%) patients had comorbidities and $28(30.43 \%)$ did not have other diseases. Among patients with associated diseases, $44(68.75 \%)$ had only one comorbidity, $18(28.12 \%)$ had two and two (3.12\%) had three or more. Of the comorbidities, we found $30(46.87 \%)$ cases of hypertension, $23(35.93 \%)$ of sedentary lifestyle, 20 (31.25\%) other diseases (hemoglobinopathies, bronchitis, depression, hypothyroidism and previous local fractures), 10 (15.62\%) cases of diabetes mellitus, five (8.06\%) of cardiomyopathies and one $(1.56 \%)$ of liver disease. There were no cases of previous DVT or family history of VTE. Our sample consisted of 28 (43.75\%) patients who used antihypertensive drugs prior to the surgical procedure, 10 (15.62\%) hypoglycemic agents, four (6.25\%) anticoagulants, two (3.12\%) hormones, one (1.56\%) corticoid, one (1.56\%) contraceptive, and one $(1.56 \%)$ herbal. No prosthesis was cemented and, regarding the type of THA, 72 (65.45\%) patients underwent THA with normal prosthesis, 25 (22.72\%) of the metaphyseal type, and 13 (11.81\%) were submitted to a prosthesis revision.

All 92 patients were adequately submitted to our institution's VTE and DVT prevention protocol (Figure 1). According to this protocol, THA are considered high risk procedures. 


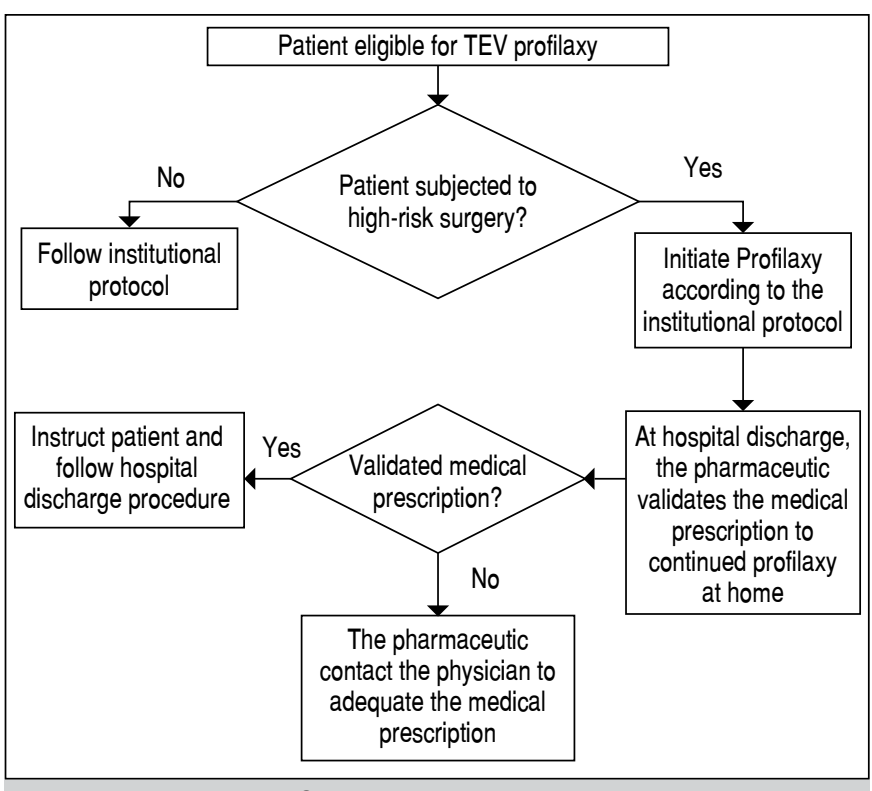

Figure 1. Prophylactic Scheme of Venous Thromboembolism.

The contraindication for the use of pharmacological methods was: active bleeding or active peptic ulcer, use of anticoagulation, heparin allergy or thrombocytopenia, coagulopathy (thrombocytopenia $<100,000 / \mathrm{mm}^{3}$ or $\left.\mathrm{NR}^{\circ}>1.5\right)$, uncontrolled systemic arterial hypertension $(>180 \times 110 \mathrm{mmHg})$, persistent renal failure (clearance $<30 \mathrm{ml} / \mathrm{min}$ ), recent intracranial or ocular surgery $<2$ weeks, CSF collection in the last 24 hours.

Contraindications to adjuvant methods were: concomitant open fractures, severe heart failure, peripheral arterial insufficiency of the lower limbs and infection or ulcer in the lower limbs.

As chemoprophylaxis with LMWH and UFH, we recommend enoxaparin $40 \mathrm{mg}$ subcutaneously administered once a day or unfractionated heparin at a dose of 5,000 IU subcutaneously administered every 8 hours, associated with mechanical prophylaxis. The beginning of chemoprophylaxis is 12 hours before or 12 to 24 hours after the surgical procedure, lasting for seven to 10 days.

For cases of hip arthroplasty, we used chemoprophylaxis with LMWH for 28 to 35 days, associated with the use of pneumatic compression (at least 18 hours a day during the period in which the patient is hospitalized). The use of elastic compression stockings is recommended as soon as possible. Walking is initiated and supervised by the physiotherapy team on the first day of the postoperative period, considering the individual walking capacity of each operated patient

For the detection of DVT, elements of clinical evaluation and imaging exams are used. Clinical analysis consists of: detection of lower limb pain; palpation of the affected region; observation of distal perfusion; palpation of peripheral pulses, observation of edema; positivity for specific propaedeutic maneuvers such as Homan's sign, flag sign, calf jamming; hyperemia, pallor or local heat. Among the complementary exams, when thrombosis is suspected, the following are used: plain radiographs, ultrasonography, arterial and venous color Doppler, magnetic resonance and laboratory tests.

\section{RESULTS}

We observed only one (1.09\%) patient with DVT in our sample. Due to the fact that we found only one case of DVT, it was not possible to ascertain the relative risk of onset of this condition in relation to factors inherent to our patients such as age, use of medications, postoperative complications, use of medications, comorbidities and number of comorbidities.

It was not possible to contemplate our secondary objective of verifying whether the rates of this complication would be related to primary replacement surgeries or revision surgeries.

Regarding postoperative complications, only one case of late infection was reported, in which the prosthesis was removed and surgical revision was performed successfully.

\section{DISCUSSION}

The THA, an established orthopedic procedure, adequately solves hip affections in cases of primary or secondary degenerative arthritis. Its use is closely related to the general aging of the world population and the improvement of techniques and materials used in these salvage operations, making these patients' satisfaction higher, as well as increasing the durability of the effects of this technique.

The first adverse event on this list is considered the most common and is considered the leading cause of death in the first three months of the postoperative period. DVT is responsible for the large number of deaths, especially those that occur suddenly, resulting from pulmonary embolism and the sum of other injuries that are often undiagnosed.

Our study demonstrated that the protocol used was efficient. However, we know there are cases where DVT presents itself asymptomatically, where subclinical forms of this entity do not clearly expose the symptoms of its onset, which include venous obstructions between $10-40 \%$. Therefore, this pathophysiological information could not manifest and, therefore, not be diagnosed.

In our view, an investigative protocol of this occlusion pattern should be carried out. Possibly, some of our patients may have developed this pattern of occlusion, which would justify our low incidence.

We believe that the best and lowest cost-benefit for VTE prevention is related to the systematic use of intermittent pneumatic compression. This finding is in line with the opinion of other authors who consider that the association with the use of acetylsalicylic acid (ASA) increases its preventive power, ${ }^{10}$ especially if used within the first 24 hours after surgery. ${ }^{11}$ We found divergent opinions regarding the use of this protocol, as there is a fear that its application will not be enough to prevent DVT.12

When consulting the literature, it is evident that it is not yet defined as to which drug agent actually has superiority in terms of collective efficacy and safety when compared to each other. ${ }^{13}$ The use of enoxaparin (ENX), as well as other substances that act in the coagulation cascade, such as ASA, rivaroxaban (RVX), ${ }^{14,15}$ Fondaparinux (FPX) or apixaban (APX), have been proven to reduce the incidence of VTE. 13,15,16 However, each of these substances has a series of complications, such as increased risk of massive bleeding. We know that ENX and ASA have similar bleeding risks, both of which had better results when compared with the use of RVX.17

Another factor to be considered in the use of these substances is the inherent cost of DVT. The financial impact of health policies, especially with regard to prevention, of the treatment of installed thromboembolic event and the cost of medications must be considered, as the use of THA has increased in the world population. ${ }^{18}$

One must emphasize that the effectiveness of these measures varies according to the patient's profile, surgical technique used, operative time ${ }^{16}$ patient compliance ${ }^{19}$ as well as their clinical evaluation, since the use of ENX causes laboratory alterations in liver function, in $\mathrm{DHL}$, in $53 \%$ of the cases, albeit without clinical repercussions. ${ }^{20}$ Thus, an effective measure in preventing VTE and reducing hospital time, in addition to reducing other adverse events, is the early 
mobilization of the patient associated with the use of intermittent pneumatic compression. ${ }^{21}$

It is worth emphasizing that the risk of VTE in revision arthroplasties is greater, as the magnitude and complexity of the procedure are considered to increase the risk of occurrence of this event. ${ }^{12}$ We believe the use of the same protocol we used can determine the same positive results achieved in primary and revision THA. We did not observe any cases of DVT in the group of individuals undergoing revision THA.

At our institution, we value the following active factors that increase the risk of developing VTE: stroke, cancer, central venous catheter, inflammatory bowel disease, severe respiratory disease, smoking, peripheral arterial insufficiency, admission to a care unit intensive, $\mathrm{BMI} \geq 30 \mathrm{~kg} / \mathrm{m}^{2}$, rheumatic disease, pregnancy, puerperium, class III or IV congestive heart failure in crisis, previous history of VTE, infection, paresis or paralysis of the lower limbs, chemotherapy, hormone therapy, hormone replacement, contraceptive, syndrome nephrosis, thrombophilias, varicose veins and venous insufficiency.

We believe that the combination of drug and physical methods determines favorable rates in the prevention of thromboembolic phenomena. In general, we found studies whose methods are similar to those adopted by Torres, Bautista and Lins, with incidences ranging from $0 \%$ to $3 \%{ }^{10-12}$

\section{CONCLUSION}

The use of thromboprophylaxis for DVT is essential against the appearance of this complication after performing procedures such as THA. The institution of different prevention protocols determined, according to the literature, a significant reduction in its incidence.

However, the most effective method for preventing DVT has not yet been determined in the orthopedic literature, as in several studies opinions are contradictory regarding the best protocol, medication or mechanical therapy.

The association of prophylaxis methods, whether mechanical or chemical, seems to be superior when compared to isolated therapies. Our research detected only one case in one (1.09\%) patient among the 92 that make up our sample, which presupposes that:

1. The protocol used was effective

2. The use of the same protocol, in cases of THA review, can determine similar positive results when compared to those of primary total hip arthroplasty.

It was not possible to determine whether the risk of DVT would be greater in revision THAs when compared to primary THAs.

We also could not possible to determine the relative risk of DVT onset in relation to patients' age, comorbidities, BMI, complications and revision surgeries

AUTHORS' CONTRIBUTIONS: Each author contributed individually and significantly to the development of this article. VMM: literature review, data collection and analysis, article writing; MBM: literature review, data collection, article writing; NGB: literature review, data collection, article writing; ETT: research project development, data analysis, review of the article to be published; ETB: review of the article to be published.

\section{REFERENCES}

1. Kozak LJ, Hall MJ, Owings MF. National hospital discharge survey: 2000 annual summary with detailed diagnosis and procedure data. Vital Health Stat 13. 2002;(153):1-194.

2. Menzin J, Richner R, Huse D, Colditz GA, Oster G. Prevention of deep-vein thrombosis following total hip replacement surgery with enoxaparin versus unfractionated heparin: a pharmacoeconomic evaluation. Ann Pharmacother. 1994;28:271-5

3. Imperiale T, Speerof T. A meta-analysis of methods to prevent venous thromboembolism following total hip replacement. JAMA. 1994;271:1780.

4. Baruzzi ACA, Hamerschlak N. Trombose venosa profunda. In: Knobel E, editor Condutas no paciente grave. São Paulo: Atheneu; 1998. p. 218-27.

5. Fraser JD, Anderson DR. Deep venous thrombosis: recent advances and optimal investigation with US. Radiology. 1999;211:9-24.

6. Handoll HHG, Farrar MJ, McBirnie J, Tytherleight-Strong G, Awal KA, Milne AA, Gillespie WJ. Heparin, LMWH and physical methods for preventing DVT and PE following surgery for hip fractures. Oxford: The Cochrane Colaboration; 1997.

7. Nurmohamed MT, Rosendaal FR, Büller HR, Dekker E, Hommes DW, Vandenbroucke JP, Briët E. Low-molecular-weight heparin versus standard heparin in general and orthopedic surgery: a meta-analysis. Lancet. 1992;340:152-6.

8. Caprini JA, Arcelus JI, Reyna JJ, Motykie GD, Mohktee D, Zebala LP, Cohen EB. Deep vein thrombosis outcome and the level of oral anticoagulation therapy. J Vasc Surg. 1999;30:805-11

9. Kellgren JH, Lawrence JS. Radiological Assessment of Osteo-Arthrosis. Ann Rheum Dis. 1957;16(4):494-502.

10. Torres RT, Saunders R, Ho KM. A Comparative cost-effectiveness analysis of mechanical and pharmacological VTE prophylaxis after lower limb arthroplasty in Australia. J Orthop Surg Res. 2019;14(1):93.

11. Lins RC. Rolim Filho EL, Oliveira FSC, Santos SM, Rolim TLV, Kreimer F. Prospective study of aspirin for thromboembolism prophylaxis in total hip arthroplasty. Acta Ortop Bras. 2018;26(2):86-90.
12. Bautista M, Muskus M, Tafur D, Bonilla G, Llinás A, Monsalvo D. Thromboprophylaxis for hip revision arthoplasty: can we use the recommendations for primary hip surgery? A cohort study. Clin Appl Thromb Hemost. 2019;25:1-7.

13. Lu X, Lin J. Low molecular weight heparin versus other anti-thrombotic events after total hip or total knee replacement surgery: a systematic review and meta-analysis. BMC Musculoskelet Disord. 2018;19(1):322.

14. Kanan OS, Schwartsmann CR, Boschin LC, Conrad S, Silva MF. Estudo comparativo entre rivaroxaban e enoxaparina na profilaxia de tromboembolismo venoso profundo em pacientes submetidos à artroplastia total do quadril. Rev Bras Ortopedia. 2008;43(8):319-28

15. Moon $\mathrm{KH}$, Kang JS, Youn YH. Is the oral chemical prophylaxis necessary for the prevention of venous thromboembolism after joint arthroplasty in a korean population? Hip Pelvis. 2019;31(3):150-7.

16. Hur M, Park SK, Koo CH, Jung ED, Kang P, Kim WH, et al. Comparative efficacy and safety of anticoagulants for prevention of venous thromboembolism after hip and knee arthroplasty. Acta Orthop. 2017;88(6):634-41.

17. Lindquist DE, Stewart DW, Brewster A, Waldroup C, Odle BL, Burchette JE, et al. Comparison of postoperative bleeding in total hip and knee arthroplasty in patients receiving rixaroxaban, enoxaparin, or aspirin for thromboprophylaxis. Clin Appl Thromb Hemost. 2018;24(8)1315-21.

18. Agaba P, Kildow BJ, Dhotar H, Seyler TM, Bolognesi M. Comparison of postoperative complications after total hip arthroplasty among patients receiving aspirin, enoxaparin, warfarin, and factor Xa inhibitors. J Orthop. 2017;14(4):537-43.

19. Wiznia DH. Patient compliance with deep vein thrombosis prophylaxis after total hip and total knee arthroplasty. Hematol Rep. 2019;11:7914.

20. Wink FV, Schwartsmann CR. Avaliação da função hepática em pacientes submetidos à artroplastia total do quadril em uso de enoxaparina. Rev Bras Ortopedia. 2010;45(2):148-50.

21. Chua MJ, Hart AJ, Mittal R, Harris IA, Xuan W, Naylon JM. Early mobilization after total hip or knee arthroplasty: a multicenter prospective observational study. PLoS One. 2017;12(6):e0179820. 